Vol. 5, No. 3-4, 2019

Yaroslav Kusyi ${ }^{1}$, Oleh Lychak $^{2}$, Volodymyr Topilnytskyy ${ }^{3}$, Miroslav Bošanský ${ }^{4}$

1. Department of Mechanical Engineering, Lviv Polytechnic National University, Ukraine, Lviv, S. Bandery Street 12, E-mail: jarkym@ukr.net, ORCID 0000-0001-5741-486X

2. Department of Methods and Tools for Acquisition and Processing of Diagnostic Signals,

Karpenko Physico-Mechanical Institute of the NAS of Ukraine, Ukraine, Lviv, Naukova Street 5,

E-mail: olehlychak2003@yahoo.com, ORCID 0000-0001-5559-1969

3. Department of Designing and Operation of Machines, Lviv Polytechnic National University, Ukraine, Lviv, S. Bandery Street 12, E-mail: topilnvol@gmail.com, ORCID 0000-0001-5246-3400

4. Institute of Transport Technology and Designing, Slovak University of Technology,

Slovak Republic, Bratislava, Námestie slobody Street 17, E-mail: miroslav.bosansky@stuba.sk

\title{
DEVELOPMENT OF THE FINISHING AND STRENGTHENING TECHNOLOGICAL OPERATIONS USING SADT-TECHNOLOGIES
}

Received: September 12, 2019 / Revised: November 30, 2019 / Accepted: December 28, 2019

(C) Kusyi Ya., Lychak O., Topilnytskyy V., Bošanský M., 2019

Abstract. The rational design of technological processes of parts manufacturing in single and small-scale production is inefficient without wide introduction of modern tools of part manufacturing automation with modern computer-based equipment and software. It is desirable to carry out of automated synthesis of single route technological processes with minimal influence of the operator on the technological environment. The technology of computer-aided design of technological processes is used to develop effective algorithms of functioning of adapted systems for control of technological processes and their implementation when taking into account interrelations with the technological environment. Automated development of technological environments of a given level of design concerning a dedicated technical system is possible on the basis of their rational functional models, created by means of CALS-technologies. The rational use of the SADT methodology with application of the principle of decomposition and development of the SADT-diagrams allows to solve the given technical problems. Therefore, the purpose of this paper is to develop and study the vibrational-centrifugal surface strengthening at the finishing and hardening technological operation to provide the required quality parameters and operational characteristics of the parts. The object of this research is a finishing and hardening technological operation. The subject of this research is method and parameters of vibrational-centrifugal surface strengthening to provide the required quality parameters and operational characteristics of the parts. The development of SADT diagrams allows to divide the technological process to technological operations, cuttersetting positions, technological steps, main machining steps etc. In this paper the principles of control of technological operation for vibration-centrifugal strengthening of surfaces of parts are suggested. The experimental device for machining of inner surfaces of parts is described. The initial and detailed model of the operation of the vibrational-centrifugal strengthening is offered. Statistical and structural analysis of technological process made it possible to establish the influence of the parameters of the vibrational-centrifugal strengthening on the geometric and physical-mechanical parameters of the surface quality and associated operational characteristics. Further research in that field will be related on the development of practical recommendations for using of the vibrational-centrifugal surface treatment for improving of the geometric and physical and mechanical parameters of parts surfaces.

Keywords: technology of computer-aided design of technological processes, life cycle of a part, SADT-technology, quality parameters, vibrational-centrifugal surface strengthening. 


\section{Yaroslav Kusyi, Oleh Lychak, Volodymyr Topilnytskyy, Miroslav Bošanský}

\section{Introduction}

The technology of computer-aided design of technological processes (TCADTP) is widely used for development of the algorithms for the functioning of digital control systems of technological processes as well as research of the dynamics and structural and stressed state of parts' material for implementation of a single technological processes or their classes with specified quality parameters when using the considered technical tools without full-scale modelling [1].

The priority of TCADTP is a formation of technical requirements for separate elements of the technological environment during the development of new technological processes by using the existing tools for design and technological support of production. Another important priority of TCADTP is a formation of technical requirements for the whole complex "Control System - Technological Environment" for the tools for designing and technology producing at the early stages of their projection. This allows to provide required technical and economic indicators during realization a given class of technological processes [2], [3].

The basis of TCADTP is the method of analytical synthesis of closed-loop controls. Control algorithms obtained by means of analytical synthesis of closed-loop controls, allow to ensure at the substage of synthesis defined characteristics of stability and quality of control processes, and at the stage of modelling established or achievable accuracy indicators [1], [2].

\section{Problem statement}

The quality parameters of the mechanical engineering parts are characterized by the dimensional accuracy, quality parameters of surface layer, operational characteristics and reliability indicators. Providing of the production quality is the most important problem of modern mechanical engineering [4]-[6].

Quality parameters of the machine details are closely related with the sub-stages and stages of the Life Cycle of a Part (see Fig. 1).

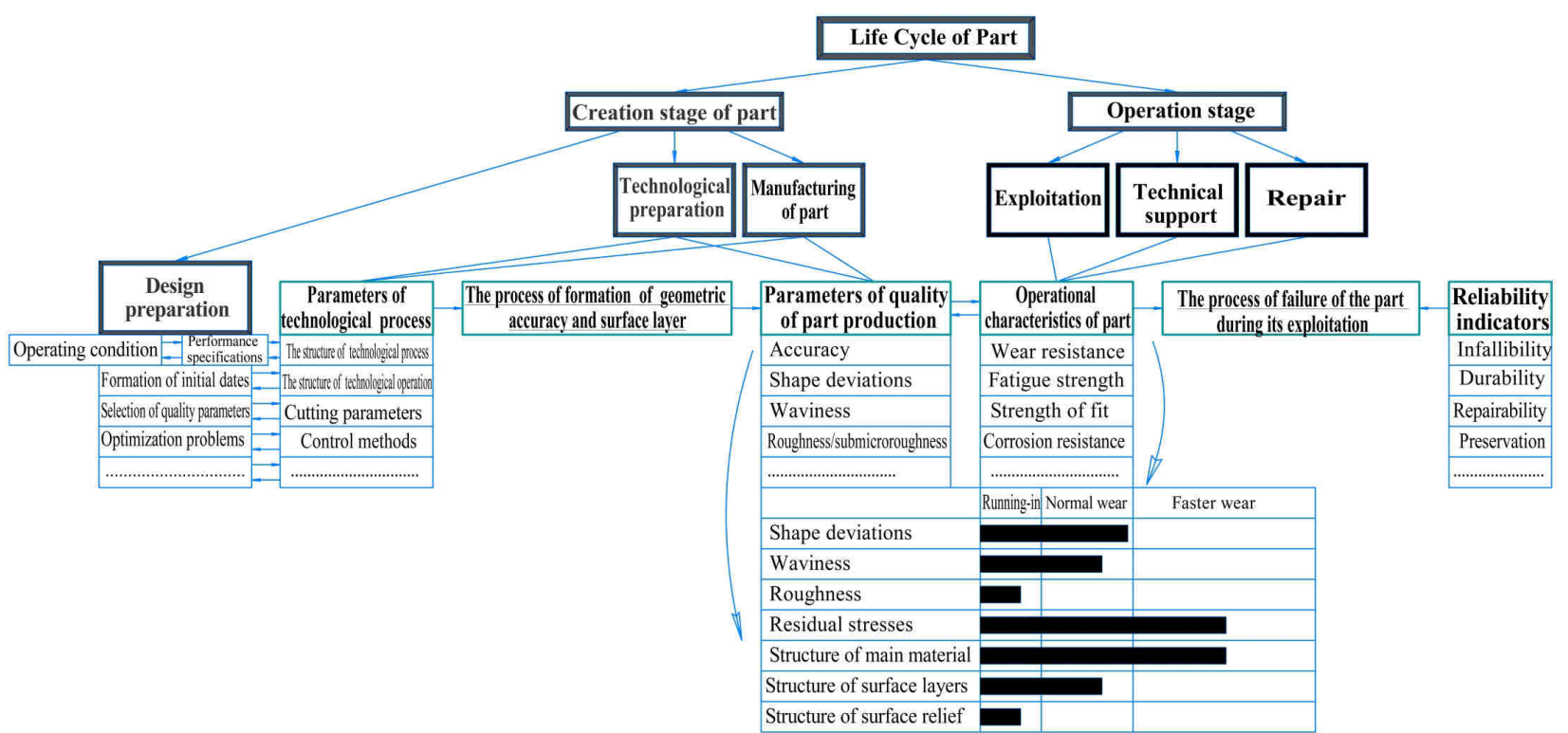

Fig. 1. Interrelationships between parameters of technological process, geometric accuracy and surface layer parameters, operational characteristics and reliability indicators

TCADTP, because of its composition, structure, the initial controls data and obtained results can be considered to some extent as a modification of SADT-technology (SADT - Structured Analysis and Design Technique) [7], [8]. In this case, TATPP provides the expansion of the range of tasks to be solved and the reduction of the time frame both at the technological preparation substage and at the creation stage of the Life Cycle of a Part as a whole [9]-[11]. 
SADT technologies have a number of advantages if compared to other approaches to solve the complex problems of structural analysis and synthesis fortechnology production modelling. The main advantages which had led to the choice of SADT technology as the main tool of solving engineering problems are [3], [8]:

1) strict formalization of the actual process of design provides convenience of receiving, perception and analysis of models, ease of integration of models of different levels or received / provided by various developers;

2) satisfactory compromise between the visualization of models and their information content;

3) developed system of editing and correction - both in terms of the convenience of entering changes at any level of the chart hierarchy, and in terms of accounting for them on the model levels associated with the editable element of the chart;

4) significant convenience of diagram creation, which provides graphic capabilities during block formation by means of modern software and automatic representation of graphic information in accordance with the technological requirements.

SADT-technologies have two main advantages for solving scientific and engineering classes of problems. They allow to develop technologies of design of technological processes as well as use the obtained results for design of technological processes of production of other parts. The purpose of the technology provided by means of the SADT-approach is the design of multifactor technological processes, which is optimized for a variety of quality parameters [8], [9].

The structural analysis method is a priority method for development and investigates of the technical systems, in that complex production and technological systems. The abbreviation of SADT is used to denote this method, its other name is the SADT-diagram method [3], [7], [8]. That method provides for a consistent detailed analysis of the system under consideration "from top to bottom".

The different levels of analysis of the projected system are highlighted using SADT-diagrams method. The processes detalization is provided during lowering levels with the equivalence preserving of the previous level. Technological Environment is analysed together with the system review and consistent detailing of system structure. The development of several models with interconnections between them details the complete description of the system. Each model is provided with a graphical and text description. The object of analysis, which is depicted by a rectangle in the scheme, is either - the projected system (at the upper level of studies) or its part (at the lower level). The environment is represented by arrows (input, output, control and mechanism) directed to or from the rectangle [12], [13].

The SADT method, along with other universal methods, only recommends how to organize and provide the analysis process. It does not give any recommendations on how to split/separate an object into parts. This feature of SADT is closely related to the peculiarities of each subject area, and requires a thorough knowledge not only of the SADT-methodology, but also the essence of the problem under consideration. Specific recommendations should be developed for each subject area, that reduce creative work, while increasing labor productivity in the design or analysis of the system at the technological preparation stage [14], [15].

\section{Purpose, object and subjects of research}

Application of the SADT methodology with application of decomposition principle and development of the complex of SADT-diagrams could serve as effective solution of the given technical problems of mechanical engineering.

Therefore, the purpose of the research is to develop and research the vibrational-centrifugal surface strengthening at the finishing and hardening technological operation for providing the quality parameters and operational characteristics of the parts.

The object of research is a finishing and hardening technological operation for providing the quality parameters and operational characteristics of the parts.

The subject of research is the method and parameters of vibrational-centrifugal surface strengthening for the technological providing of the quality parameters and operational characteristics of the parts. 


\section{Development of the SADT-diagram for "creation stage" of a part in Life Cycle of a Part}

Decomposition of object of technological process is the division of the simulated object into its structural parts (blocks and arcs, elementary diagram etc.). The process of decomposition of limited object consists of the following substages [7]: selection of a diagram block; consideration of an object defined by particular block of a diagram; creation of a new diagram; identification of disadvantages of a new diagram; creation of alternative decompositions; adjustment of a new diagram; adjustment of all the diagrams associated with particular diagram.

Decomposition forms boundaries, and each block in the SADT is considered as a formal boundary of some part of the investigated system. The block and arcs determine the exact boundary of the diagram. The diagram limit represents the decomposition of that block. The decompoused unit is called the "parent unit" and the diagram contained it is called the "parent diagram". Thus, the SADT-diagram is the decomposition of some limited object [8].

The SADT-diagram of 0-level for technological process planning consist of following data: input (I), control (management) $(C)$, mechanism for control realization $(M)$ and output $(O)$ data with following detalizations: $I_{1}$ - design and engineering documentation for part; $I_{2}$ - the technological system; $I_{3}-$ the parameters of the machining material; $C_{1}$ - time for designing; $C_{2}$ - productivity; $C_{3}-\operatorname{cost}$ price; $M_{1}-$ set of mathematical models for the technological system; $M_{2}$ - set of modelling software tools; $M_{3}-$ data base for materials; $M_{4}$ - data base for instruments; $M_{5}$ - staff of CAD department; $O_{1}$ - technological process planned with technical requirements; $\mathrm{O}_{2}$ - control or input correction requirements (see Fig. 2) [9].

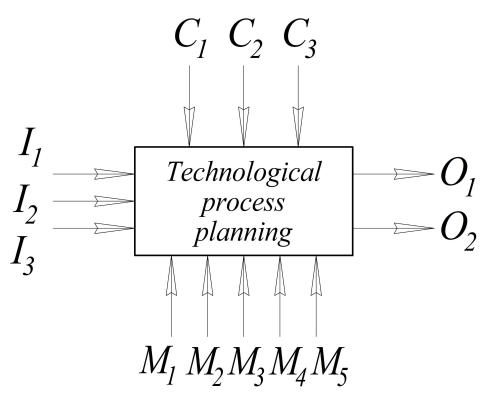

Fig. 2. The SADT-diagram of 0 level

The further decomposition of the technological process, carried out on the basis of SADT-technology, allows to obtain a set of SADT-diagrams [8], [16].

SADT-diagram of level A0 (see Fig. 3), formed on the basis of the traditional approach to the technological processes planning, assumes the existence of four main functions (blocks): management of substages of the creation stage of the Life Cycle of a Part (A1), variant of technological process planning (A2), evaluation of the efficiency criteria of the technological process (A3), quality assessment of the technological process (A4) [9].

At the initial phase of the technological preparation of production of part, we analyse the initial data, generated on the design preparation substage. The designer develops the design of the part, selects the material, assigns technical requirements for accuracy, quality of the surface layer and the reciprocal arrangement of the surfaces in accordance with the operational conditions of the loads.

The machine properties, that provide its service function and determine the operational properties, are formed during the technological processes of production parts by means of interaction of different technological objects [4], [17].

Technological objects include [9], [16]:

1) information objects, used on substage of technological preparation of the Life Cycle of a Part: technological solutions, descriptions and models of objects and their interactions are given;

2) material and information objects used on substage of technological preparation and substage of manufacturing of a part: description of technological processes (operations, step, etc.), schemes of the assembly of blanks; description of material technological facilities and the like; 
3) material objects used on substage of manufacturing of a part: technological equipment (basic technological equipment; machinery tools, control devices, assembly devices, vehicles, materials, semifinished parts, blanks, parts, etc.

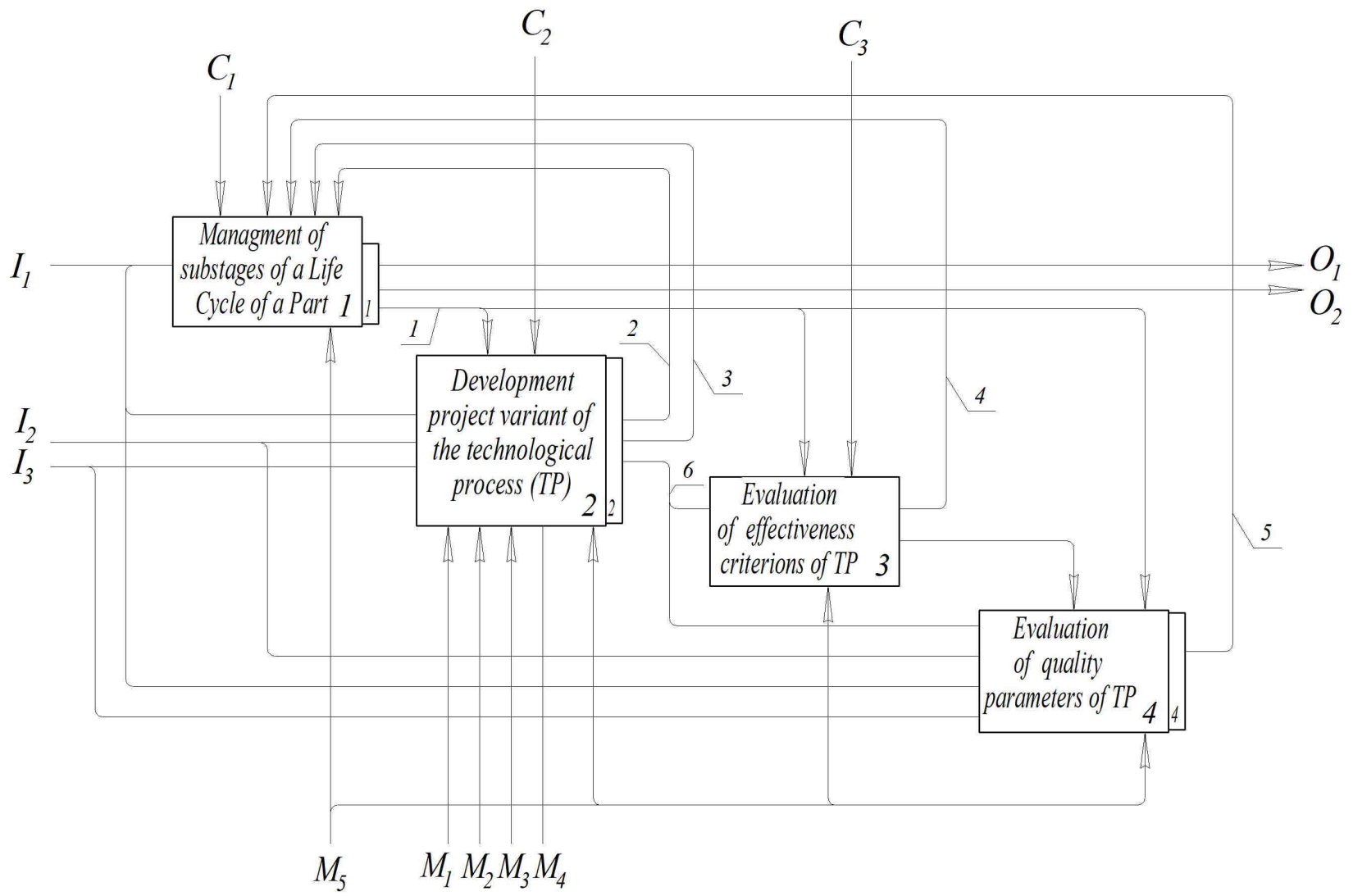

Fig. 3. SADT-diagram of A0 level: 1 - plan of the technological processes development; 2 - correction by time moments; 3 - correction by productivity; 4 - correction by economic criterions; 5 - correction by quality parameters of the technological process; 6 - version of the technological process

The technological system is formed by some set of technological objects, interacting with each other in the production of parts and assembly of the machine.

The functioning of any technological system is considered as the interaction of its investigated (defined) element with the environment, which form technological objects of a given or other technological systems.

The technological environment is a set of technological objects that interact with the investigated (defined) technological object at a separate stage of production of parts or assembly of the machine [9].

Thus, the operational characteristics, the maintenance of which is one of the criteria of the efficiency of technological process, are providing as a result of the interrelation of the processed product with the technological environment.

The detailing of the A2 function (see Fig. 3) - "Development of the variant of the technological process" is the most difficult. A SADT-diagram of A2 level (see Fig. 4) is the result of the decomposition of that blocks, where the input $\left(I_{1}-I_{3}\right)$ for A2 block, controlling by design time $\left(C_{1}\right.$ is output of block A1) and performance $\left(C_{2}\right)$ data, required costs or mechanisms $\left(M_{1}-M_{5}\right)$, as well as the initial information or the specified technological process (without its cost), or requirements for adjusting input or control data are presented [9].

It is established [3], [16] that the SADT technology extends on the development of processes of machining and assembly of a parts as well as on preparation, maintenance and interoperating transition processes.

The function «Modelling of technological process» (A23) is subjected to detailed analysis and structuring when developing design technology. SADT-diagrams of A23 level (see Fig. 5) is the result of such an analysis. 
Yaroslav Kusyi, Oleh Lychak, Volodymyr Topilnytskyy, Miroslav Bošanský

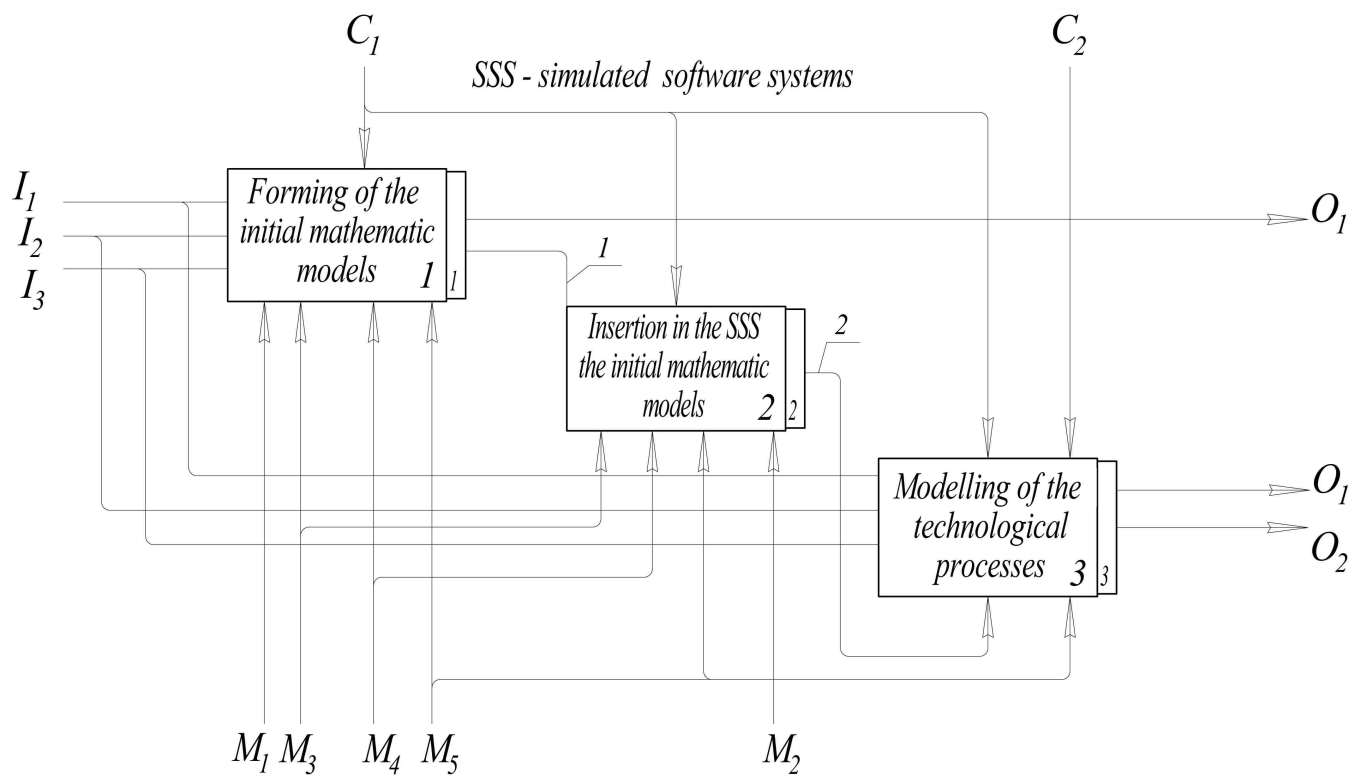

Fig. 4. SADT-diagram of A2 level: 1 - complex of mathematical models; 2 - modelling software complex

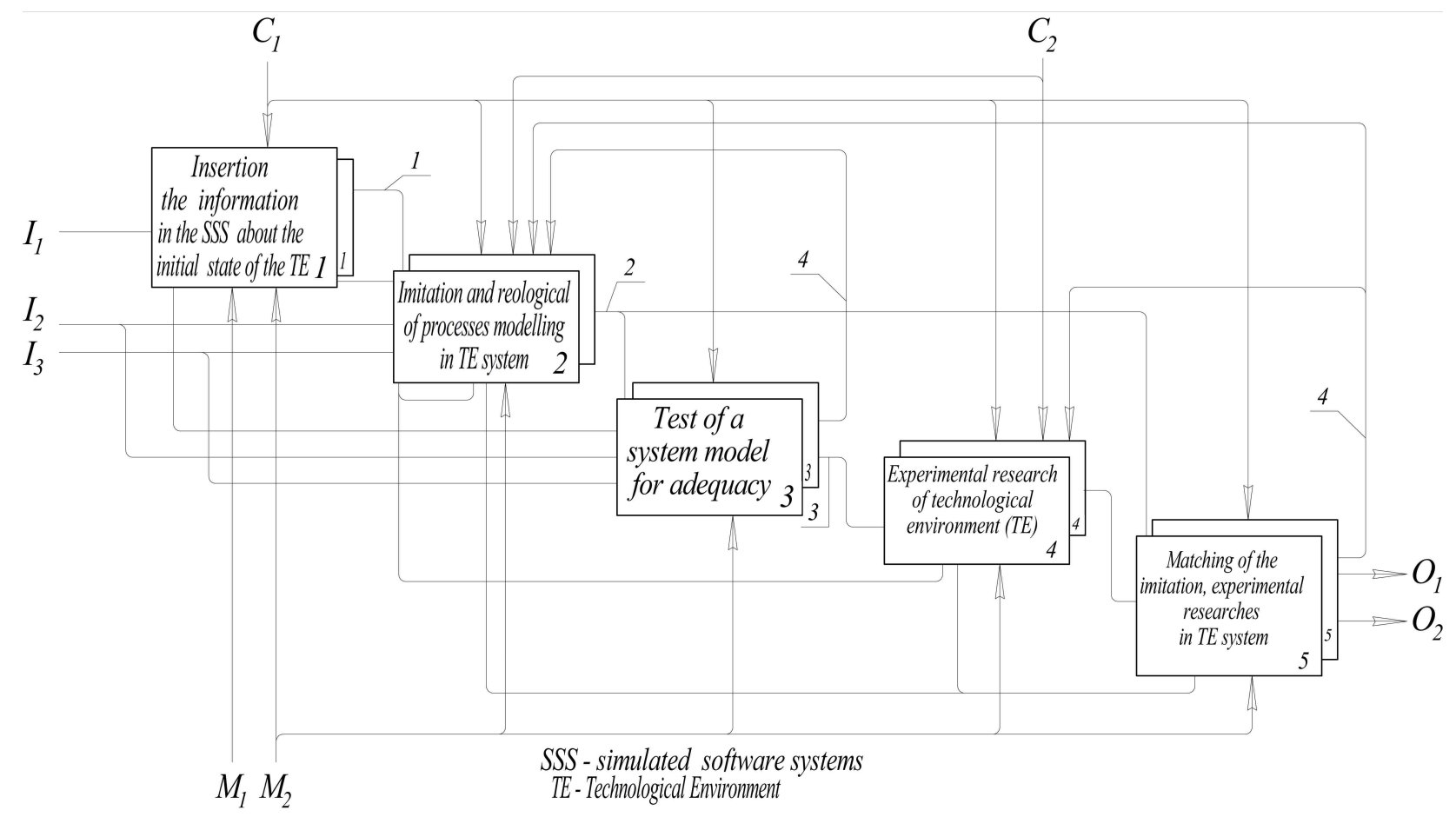

Fig. 5. SADT-diagram of A23 level: 1 - modelling software complex; 2 - transient conditions; 3 - model is adequate; 4 - requirements for adjustment of simulation conditions

Further decomposition allows to reach the levels of technological operation, technological step, main machining step, supporting step, etc.

\section{Development of the principles for management of multifactor technological operation using SADT-technologies}

The technology is decisive in the providing of quality parameters. It is established [3] that at the correct cutting parameters considerably increases durability of the parts. While incorrect cutting parameters and/or wrong estimation of the accumulation of defects on previous operations can lead to the destruction of the surface layer of part at the manufacturing stage or even the early destruction of the part at the operation stage (see Fig. 6). 


\begin{tabular}{|c|c|c|c|}
\hline $\begin{array}{c}\text { Technological process } \\
\text { characteristics (cutting } \\
\text { parameters, technological } \\
\text { shedule, .....) }\end{array}$ & $\begin{array}{c}\text { Quality parameters } \\
\text { (accuracy, quality } \\
\text { of surface layer, .....) }\end{array}$ & $\begin{array}{l}\text { Operational characteristics } \\
\text { (wear resistance, fatigue } \\
\text { strength, corrosion } \\
\text { resistance, ....) }\end{array}$ & $\begin{array}{l}\text { Realibility parameters } \\
\text { (infalibility, } \\
\text { duralibility, repairability, } \\
\text { preservation) }\end{array}$ \\
\hline
\end{tabular}

Fig. 6. Dependence of the reliability parameters on the degree of the technological process (schematically)

Therefore, the structure of the technological process has a direct and significant influence on the formation of quality parameters of the part. However, the technological modes of finishing and hardening operations have an important role in the formation of the dimensional accuracy, quality parameters of surface layer, operational characteristics and reliability indicators. However, the relations between all parameters are complex, multistage and not obvious (see Fig. 6).

We transform the scheme of reliability indicators dependence on the degree of technological process (see Fig. 6) in the SADT-diagram of the A234 level by means of SADT-technologies (see Fig. 7).

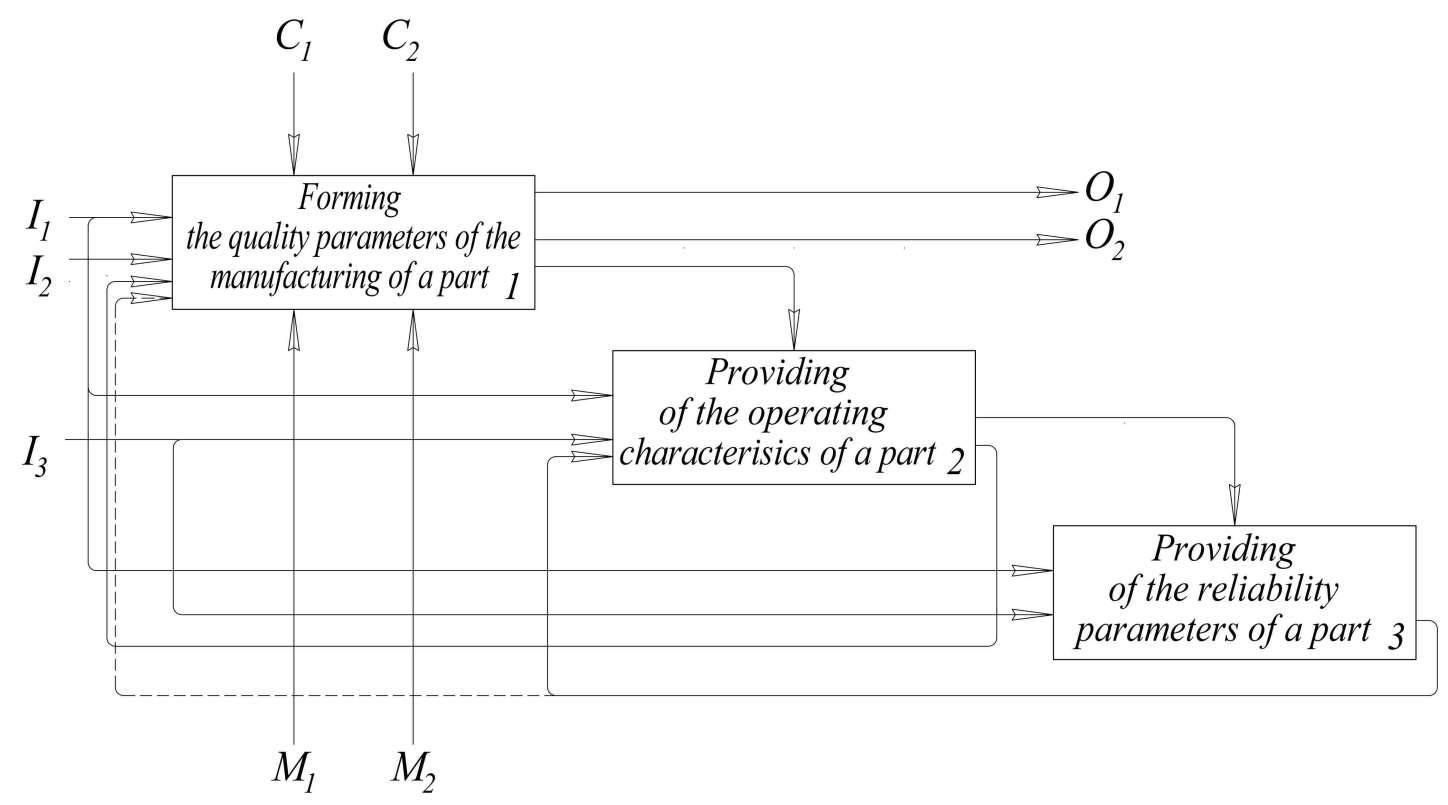

Fig. 7. SADT-diagram of A234 level for ensuring of quality parameters of the part

The scheme for providing of quality parameters for technological process, consists of consecutive operations - from the blank operation (0) to the final (n) ones (see Fig. 8) [18].

The set of values $\mathrm{Y}_{01}, \mathrm{Y}_{02}, \ldots, \mathrm{Y}_{0 \mathrm{j}}$ serves as the initial parameters for the technological process. The set of $\mathrm{m}$ output parameters $\mathrm{X}_{1}, \mathrm{X}_{2}, \ldots, \mathrm{X}_{\mathrm{m}}$ are obtained as a result of that technological process in accordance to the technical requirements. The parameter $\mathrm{P}_{0}(\mathrm{t})$ indicates the probability of providing of established technical requirements for the blank operation of the technological process. $\mathrm{P}(\mathrm{t})$ is the probability of being out of tolerance any of the specified parameters within the specified time period $\mathrm{t}=\mathrm{T}$. The output parameters are obtained during the processing of the blank. They are intended, as a rule, after each technological operation (see Fig. 8).

The special features of the output parameters of the entire process have certain features [18]:

1. Final (finishing and hardening) operations have a significant influence on the formation of the initial parameters. The parameters controlled by intermediate operations are usually changed and their value does not play a significant role (parameters of I group, see Fig. 8). The exception are the characteristics of the material, which are the starting parameters of the process, but also determine its final properties.

2. Most parameters of the finishing and hardening technological operations directly determine the reliability of the technological process, since the final formation of the quality parameters of products takes place here. The probability to stay within the tolerance established parameters determine the reliability of the entire process (II group parameters, see Fig. 8). 


\section{Yaroslav Kusyi, Oleh Lychak, Volodymyr Topilnytskyy, Miroslav Bošanský}

3. Some parameters of finishing technological operations are determined by technological inheritability. Therefore, part of the output parameters (III group, see Fig. 8) is functionally related to the parameters of previous intermediate operations.

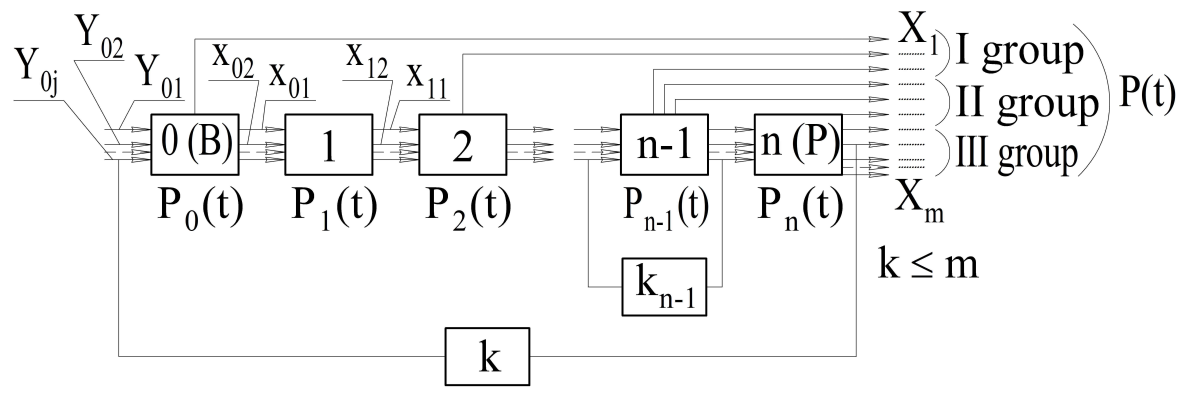

Fig. 8. The scheme of forming of quality parameters of technological process

Finishing and hardening of surface by the method of surface plastic deformation allow to minimize the influence of technological inheritability on the formation of output parameters of the part [5], [9].

The technologist must provide the accuracy of the processing and the quality parameters of the surface layer during the process operation according to the technical requirements, which forms block A2341 (see Fig. 9, a).
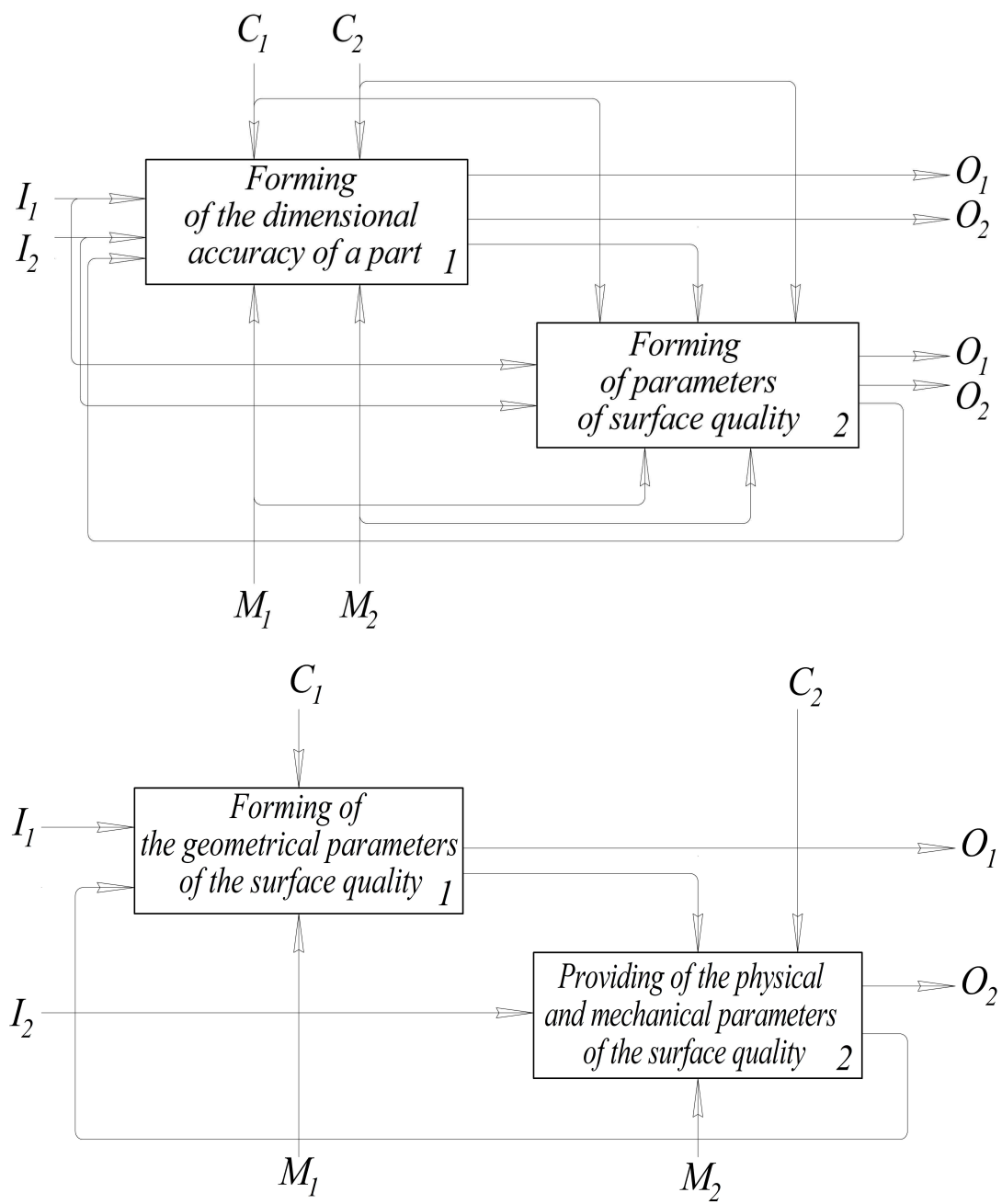

$\mathrm{b}$

Fig. 9. SADT-diagram of A2341 level for ensuring dimensional accuracy and quality parameters of surface layer for specific technological operation (a) and A23412 level for finishing and hardening operation, realized by surface plastic deformation (b) 
It is known [19], that the majority of methods of surface plastic deformation do not increase the geometric accuracy of the surface. Accuracy, achieved in the previous operation, usually is retained. Deformation of the surface layer (about 5-10 $\mu \mathrm{m}$ ) can occur due to the residual compression stresses in the surface layer during machining of thin-walled (wall thickness $-3-5 \mathrm{~mm}$ ) and uneven-stiffness parts. Uniform metal swages of 0.03-0.3 mm thickness on the face surfaces of the treated surfaces are formed due to plastic metal leaks when some methods of treatment of surface plastic deformation are using. For this subject, the main attention should be paid to the formation of quality parameters of the surface layer of the part during the experimental research of the technological operation implemented by the surface plastic deformation (see Figs. 5, 7, 9, a).

Therefore, the analysis of the function «Forming of the surface quality parameters» (level A2341) allows to form the SADT-diagram of A23412 level (see Fig. 9, b). Groups of physical-mechanical and geometric parameters of quality (see Fig. 9, $b$ ) necessary to divide for detailization on the SADT-diagram of the technological operation implemented by the surface plastic deformation [9], [14].

\section{An example of development of control models for multifactor technological operation implemented by vibration-centrifugal surface strengthening}

We consider the principles of control of technological operation with vibrational-centrifugal surface strengthening for treatment of inner cylindrical surfaces of parts.

The method of vibrational-centrifugal surface strengthening (VCSS), developed at the Lviv Polytechnic National University, refers to dynamic methods of surface plastic deformation. It is applied at the finishing and hardening operations of technological processes of part processing for providing of required technical and operational characteristics [4].

The principle diagram of the single-drive electromagnetic vibration-centrifugal strengthening device with elastic systems for processing of the inner surfaces of parts is depicted in Fig. 10.

The single-drive electromagnetic vibration-centrifugal device with elastic systems consists of two elastic-oscillating systems: the base 1 - the component of the electromagnetic drive (anchor 3 or stator 4) the reinforcers 5, 6 with deformable balls 7 . The elements of the elastic-oscillating systems are connected by torsion bars 8,9 with screwed elements $10,14,15,16$ and corresponding fits. The cover 2 protects the electromagnetic drive from mechanical damage and dirt ingress. The basing of the strengthening device in relation to the processed surface 17 is carried out using the guide rollers 11.

The inner surface of the part is strengthened in that sequence. The device is installed on the inside of the part 17 by means of special tool. Part 17 is fixed to the support platforms (not shown on figure) by means of fixing mechanisms. These platforms are situated at the different levels relative to the frame. When the current flows in coils of the solenoids 12 on stator 4, an electromagnetic field is created between the drive elements. Stator 4 is oscillating with an anchor in the opposite phases. The reinforcers 5,6 , which are attached to stator 4 and anchor 3, begin make oscillating and break-in movements with striking protruding balls 7 on the inner surface of the processed part. Contacts between the part and the reinforcers 5,6 through a small number of balls 7 leads to the development of big contact stresses in the material of the part and, as a result, its surface plastic deformation. The device moves on rollers 11 along the processed surface of the part to the platform below. The processing device is moving in the opposite direction when the platform is moved.

The statistical analysis of vibrational-centrifugal surface strengthening has resulted in the following conclusions:

1) dynamic factors primarily should be used for the control of the physical and mechanical parameters of the quality of surface layer;

2) tool movement parameters should be used for the control of the geometric parameters of the quality of surface layer.

The factors, which influence on the change of the geometrical and physical-mechanical parameters of the surface quality of the part are the feed rate $V_{S}\left(\mathrm{X}_{1}\right)$, adduced rigidity of the sections of elastic systems 


\section{Yaroslav Kusyi, Oleh Lychak, Volodymyr Topilnytskyy, Miroslav Bošanský}

$c_{a d .}\left(\mathrm{X}_{2}\right)$, the number of device passes $n\left(\mathrm{X}_{3}\right)$, the weight of the reinforcers of the device $m_{r}\left(\mathrm{X}_{4}\right)$, the current in the coils of the drive solenoids $I\left(\mathrm{X}_{5}\right)$ [4].

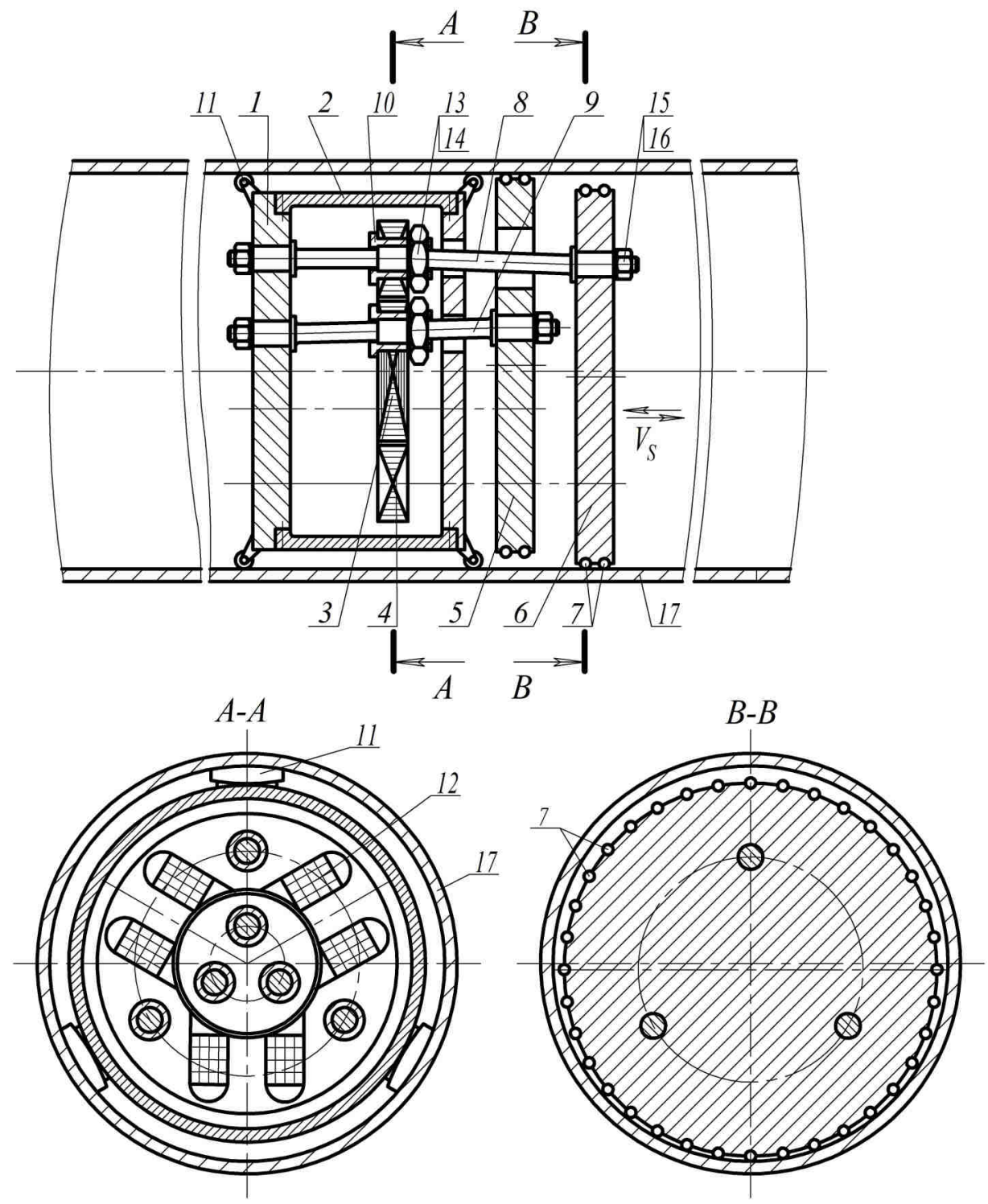

Fig. 10. The principle diagram of the single-drive electromagnetic vibration-centrifugal strengthening device with elastic systems

Low-changing indicators are voltage level on the coils of the solenoids $U(U=220 \mathrm{~V})$, the relative filling of the volume of the cross section by deformed bodies $\Delta V / V(\Delta V-$ the volume of the cross section filled with deformed bodies; $V$ - the total volume of the cross section), the diameter of the deformed bodies - iron hardened balls $d(d=10 \mathrm{~mm})$.

The influence of technological parameters of vibration-centrifugal hardening on geometric (mean arithmetic deviation of the $R a$ profile, mean step of profile irregularities $S_{m w}$, etc.) and physical-mechanical parameters of the surface quality of the part material (surface microhardness $H \mu$, thickness of the reinforced layer $a$ and degree of hardening $\varepsilon$ ) were investigated.

The limit values of technological factors are taken as following: $V_{S}=35-135 \mathrm{~mm} / \mathrm{min}$, $c_{a d .}=3.317 / 7.471 \cdot 10^{5} \mathrm{~N} / \mathrm{m}, n=1-3, m_{r}=1.8-3.0 \mathrm{~kg}, I=0.75-1.25$ A [4].

Groups of physical-mechanical and geometrical parameters of part's surface quality (see Fig. 11, b) should be separated when using the structural analysis [12] of vibro-centrifugal surface processing for the SADT-diagram (see Fig. 11, a). 
The finishing and hardening technological operation appropriately managed with the most influential technological factors.

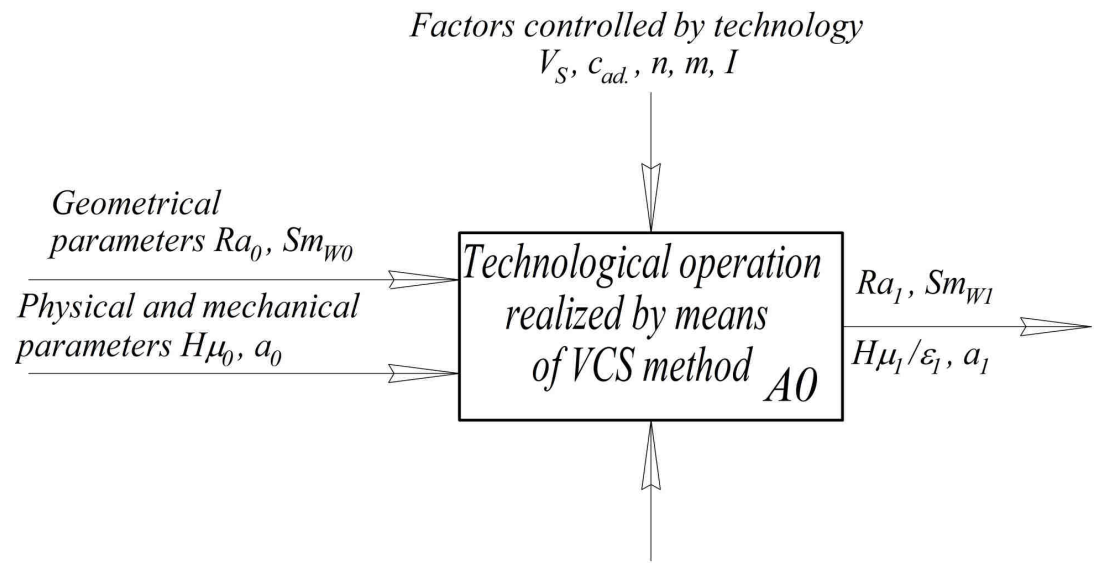

$d, \Delta V / V, U$

Hardly varying indicators

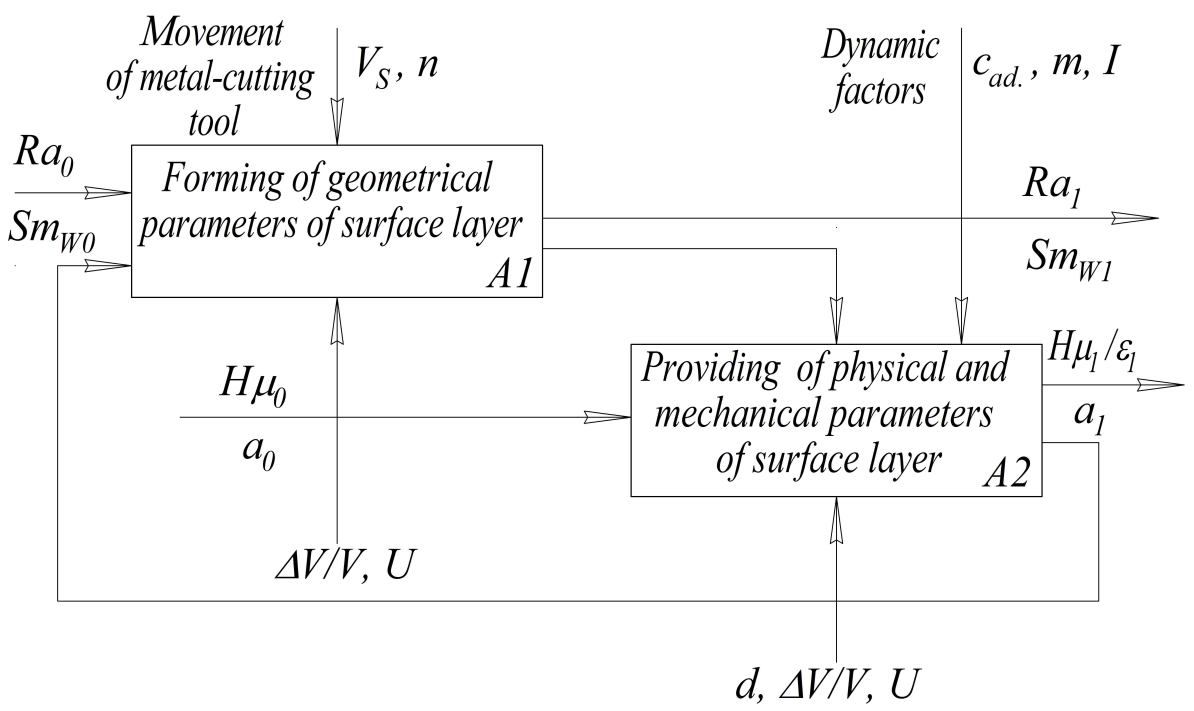

Fig. 11. Initial (a) and detailed (b) models of the finishing and strengthening technological operation by using vibro-centrifugal processing

It was established [4], that the main influence on the physical and mechanical parameters $\mathrm{Y}_{1}=H \mu$, $\mathrm{Y}_{3}=\varepsilon$ has the tool movement parameters $\mathrm{X}_{1}=V_{S}, \mathrm{X}_{3}=n$ as well as dynamic parameters $\mathrm{X}_{2}=c_{a d}, \mathrm{X}_{5}=I$. The main influence on the thickness of the reinforced layer $\mathrm{Y}_{2}=a$ has the tool movement parameters $\mathrm{X}_{1}=V_{S}, \mathrm{X}_{3}=n$ as well as dynamic parameters $\mathrm{X}_{4}=m_{r}, \mathrm{X}_{5}=I$ (see Fig. 12,a).

It was shown [4], that the main influence on the geometrical parameters of surface quality $\mathrm{Y}_{4}=R a$ and $\mathrm{Y}_{5}=S_{m w}$ has the tool movement parameters $\mathrm{X}_{1}=V_{S}$ and $\mathrm{X}_{3}=n$ (see Fig. 12, $b$ ).

We can offer following recommendation for usage of vibrational-centrifugal surface strengthening as a finishing and hardening technological operation for mechanical engineering part:

- the most influencing are factors of tool movement: the feed rate $\mathrm{X}_{1}=V_{S}$ and the number of device passes $\mathrm{X}_{3}=n$ as well as dynamic parameters: the rigidity of the sections of elastic systems $\mathrm{X}_{2}=c_{a d}$, the weight of the reinforcers of the device $\mathrm{X}_{4}=m_{r}$, the current in the coils of the drive solenoids $\mathrm{X}_{5}=I$;

- after surface strengthening, the control of geometrical parameter of quality of surface layer $R a$ should be carried out;

- visual express control of the waviness of surface microrelief $S_{m w}$;

- measurement of physical and mechanical parameters $(H \mu, a)$ at separated control examples, evaluation of the degree of hardening $\varepsilon$ ). 


\section{Yaroslav Kusyi, Oleh Lychak, Volodymyr Topilnytskyy, Miroslav Bošanský}

\section{Conclusions}

1. The planning of the rational technological processes of manufacturing of the parts is most effective with introduction of automation, CALS-technologies and PC. The development of optimal design algorithms by means of the technology of computer-aided design of technological processes (TCADTP) is possible involving theoretical and experimental researches of all substages and stages of the Life Cycle of a Part.

2. The technology of computer-aided design of technological processes can be interpreted as a modification of SADT-technology. The basis of SADT-technology is the method of analytical synthesis and analysis of closed-loop control systems. The control algorithms in the form of SADT diagrams, obtained by means of SADT technology, allow to predict the necessary characteristics of stability and quality of control processes at the substage of synthesis of technical systems. The developed software allows to provide the specified accuracy, quality parameters of the surface layer and operating characteristics of the part.

3. Control of multifactor finishing and hardening operations using optimized quality parameters of vibrational-centrifugal surface treatment are provided by means of the statistical and structural analysis of technological systems. The using of a system approach in statistical and structural analysis of technological systems optimizes the process of implementation of control of the technological operation and the required parameters of control at a particular time.

4. The scopes of further investigations will be related on the planning and implementation of experiments about the influence of technological parameters of vibrational-centrifugal surface treatment on geometrical and physical and mechanical parameters of surface quality. The practical recommendations about the selection of technological modes will be developed for the control of special processes and technical control at mechanical production and repair enterprises for improving the part quality and providing rational operational characteristics.

\section{References}

[1] Ya. M. Kusyi, "Tekhnolohichne zabezpechennia fizyko-mekhanichnykh parametriv poverkhnevykh shariv metalevykh dovhomirnykh tsylindrychnykh detalei vibratsiino-vidtsentrovym zmitsnenniam" ["The technological providing of physical and mechanical parameters of surface layers of metal long-sized cylindrical parts by means of vibrational-centrifugal strengthening"], PhD. dissertation, Lviv Polytechnic National University, Lviv, Ukraine, 2002. [in Ukrainian].

[2] Ya. M. Kusyi, "Tekhnolohichne uspadkovuvannya vlastyvostey pry zabezpechenni parametriv yakosti vyrobu v protsesi yoho vyhotovlennya" ["Technological inheritability of properties for providing of quality parameters of part during it manufacturing"], Systemni tekhnolohiyi [System Technologies], vol. 5 (124), pp. 171-184, 2019 [in Ukrainian].

[3] Ya. Kusyi, A. Kuk, and O. Kostiuk, "Use of vibration technologies for ensuring quality parameters of products surfaces", in Materials of $19^{\text {th }}$ International Conference on Thermal Science and Engineering of Serbia SIMTERM 2019, Sokobanja, Serbia, October 22-25, 2019, p. 142.

[4] I. S. Aftanaziv, L. I. Shevchuk, O. I. Strohan, A.M. Kuk, and I. L. Samsin, "Improving reliability of drill pipe by strengthening of thread connections of its elements". Naukovyi Visnyk Natsionalnoho Hirnychoho Universytetu, vol. 4, pp. 22-29, 2019.

[5] V. Blumenstein, K. Rakhimyanov, M. Heifetz, and A. Kleptzov, "Problem of technological inheritance in machine engineering", AIP Conference Proceedings, vol. 1698 (1), pp. 2-7, 2016.

[6] B. Denkena, et al., "Development and first Applications of Gentelligent Components over their LifeCycle”, CIRP Journal of Manufacturing Science and Technology, vol. 7 (2), pp. 139-150, 2014.

[7] R. H. Gubaydulina, S. V. Gruby, and G. D. Davlatov, "Analysis of the Lifecycle of Mechanical Engineering Products", IOP Conference Series: Materials Science and Engineering, vol. 142 (1), Article number 012060, 2016.

[8] M. Winkens, M. Goerke, and P. Nyhuis, "Use of Life Cycle Data for Condition-Oriented Maintenance", International Journal of Mechanical, Aerospace, Industrial and Mechatronics Engineering, vol. 9 (4), pp. 1178-1181, 2015. 
[9] A. M. Gontarz, D. Hampl, L. Weiss, and K. Wegener, "Resource Consumption Monitoring in Manufacturing Environments", Procedia CIRP, vol. 26 (1), pp. 264-269, 2015.

[10] B. Denkena, J. Schmidt, and M. Krüger, "Data mining approach for knowledge-based process planning", in Proceedings of the 2nd International Conference on System-Integrated Intelligence, Bremen, Germany, July 2-4, 2014, pp. 407-416.

[11] C. Bauerdick, M. Helfert, L. Petruschke, J. Sossenheimer, and E. Abele, "An Automated Procedure for Workpiece Quality Monitoring Based on Machine Drive-Based Signals in Machine Tools", Procedia CIRP, vol. 72 (1), pp. 357-362, 2018.

[12] V. A. Okulesskiy, Funktsionalnoye modelirovaniye - metodologicheskaya osnova realizatsii protsessnogo podkhoda [Functional modeling is the methodological basis for the implementation of the process approach]. Moscow, Russia: NITs CALS-tekhnologiy "Prikladnaya logistika" Publ., 2001. [in Russian].

[13] D. A. Marca, and C. L. McGovan, SADT: Structured Analysis and Design Techniques. New York, USA: McGraw-Hill Publ., 1987.

[14] D. A. Marca, "SADT/IDEF0 for Augmenting UML, Agile and Usability Engineering Methods", in Proc. International Conf. on Software Technologies, Seville, Spain, July 18-21, 2011, pp. 38-55.

[15] E. V. Sudov, A. I. Levin, A. V. Petrov, and E. V. Chubarova, Tekhnologii integrirovannoi logisticheskoi podderzhki izdelii mashinostroeniya [Technologies of Integrated Logistic Support of Mechanical Engineering Parts]. Moscow: Informbyuro Publ., 2006. [in Russian].

[16] Mezhdunarodnaya entsiklopediya CALS. Aviatsionnokospicheskoe mashinostroenii [International Encyclopedia CALS. Aerospace Machine Engineering]. Moscow: Nauchno-issledovatel'skiy tsentr avtomatizirovannykh sistem konstruirovaniya Publ., 2015. [in Russian].

[17] O. A. Gorlenko, and V. V. Miroshnikov. Sozdaniye sistem menedzhmenta kachestva v organizatsii [Creation of the quality management systems in the organization]. Moscow, Russia: Mashinostroenie Publ., 2002. [in Russian].

[18] Ja. Kusyj, O. Kuzin, and N. Kuzin, "Analysis of technological damageability of castings manufactured in sand molds", Technology audit and production reserves, vol. 3 (1), pp. 17-23, 2017.

[19] L. G. Odintsov, Uprochneniye i otdelka detaley poverkhnostnym plasticheskim deformirovaniyem [Strengthening and finishing of parts by means of surface plastic deformation]. Moscow, Russia: Mashinostroenie Publ., 1987. [in Russian]. 